\title{
Synthesis of Thermally Cross-Linkable Fluorine-containing Poly(aryl ether ketone)s I. Phenylethynyl Terminated Poly(aryl ether ketone)s
}

\author{
Kunio KimURA, ${ }^{\dagger}$ Ai NishichI, and Yuhiko YamashitA \\ Faculty of Environmental Science and Technology, Okayama University, \\ 3-1-1 Tsushima-naka, Okayama 700-8530, Japan
}

(Received November 22, 2001; Accepted February 12, 2002)

\begin{abstract}
Fluorine-containing poly(aryl ether ketone)s (PEKs) derived from 2,3,4,5,6-pentafluorobenzoic acid (PFBA) exhibit outstanding solubility, thermal stability, low dielectric constant, low moisture absorption and high transparency. Hence, they are expected to be available for optical and electric materials. In such applications, excellent solubility is of great advantage for making thin film and coating. Contrary to this advantage, this is of disadvantage from a point of solvent resistance. Thermally cross-linkable fluorine-containing PEKs terminated with phenylethynyl moiety (PEK-PEP) are synthesized to improve the solvent resistance in this study. Cross-linking reaction occurs over $320^{\circ} \mathrm{C}$ and it brings about not only the outstanding solvent resistance but also the increase of $T_{\mathrm{g}}$. Relationship between the cross-linking density and $T_{\mathrm{g}}$ can be fundamentally interpreted by configurational entropy theory. Furthermore, the cured PEK-PEPs possess excellent thermal stability with the $10 \%$ weight loss temperature in the range from 544 to $598^{\circ} \mathrm{C}$.

KEY WORDS Fluorine-Containing Polymer / Poly(aryl ether ketone) / Phenylethynyl Group / Cross-Linking / Solvent Resistance / Thermal Stability /
\end{abstract}

The high-performance fluorinated polymers have been receiving considerable attention as interesting advanced materials for applications as films, coatings for optical and microelectronics device, gas separation membranes and so on. ${ }^{1-3}$ Recently, poly(aryl ether ketone)s (PEKs) containing 2,3,5,6-tetrafluoro1,4-phenylene moieties were synthesized from perfluorobenzophenone. ${ }^{4}$

2,3,4,5,6-Pentafluorobenzoic acid (PFBA) is a valuable intermediate for pharmaceuticals, pesticides, perfumes, cosmetics and so on, and it is available as a commercial product. PFBA is a very useful raw material for making fluorine-containing PEKs. We had prepared novel fluorine-containing PEKs derived from PFBA and reported so far. ${ }^{5}$ These PEKs (F-PEKs) described in Scheme 1 exhibit outstanding solubility, thermal stability, low dielectric constant, low moisture absorption and high transparency. Hence, they are expected to be available for optical and electric materials. In such applications, excellent solubility is of great advantage for making thin film and coating. Contrary to this advantage, this is of disadvantage from a point of solvent resistance. Solvent resistance should be improved with keeping the good solubility and other properties. Introduction of cross-linkability into the polymer chain is one of the answers to circumvent this drawback. Numerous types of thermosets had been synthesized with terminal or pendant cross-linkable endgroups which



Scheme 1. Fluorine-containing PEKs.

were sites for network formation. ${ }^{6-15}$ It is of importance to design the cross-linkable moiety that crosslinking reaction should occur without the evolution of small volatile compounds to form the clear film and coating. Cross-linkable moieties that meet the required condition are phenylethynyl, cyanate, benzocyclobutane and so on. ${ }^{7}$

Various oligomers, such as imide, sulfone and so on, terminated by phenylethynyl moiety have been reported. ${ }^{8-14}$ Upon thermal curing, they undergo a complex reaction involving chain extension, branching and cross-linking to afford materials with attractive properties such as solvent resistance and thermal stability. The phenylethynyl group offers certain distinct advantages over other reactive groups. ${ }^{15}$

In this paper, we report the synthesis and characterization of fluorine-containing PEKs terminated with phenylethynyl moiety (PEK-PEP). 


\section{EXPERIMENTAL}

\section{Materials}

PFBA was a gift from Nippon Shokubai Co. Ltd. 2,2-Bis(4-hydroxyphenyl)-1,1,1,3,3,3-hexafluoropropane (6FBA), 4-bromophenol and phenylacetylene were obtained from Aldrich Chemical Co., Inc. 9,9Bis(4-hydroxyphenyl)fluorene (HF) was obtained from Kennedy and Klim. Co., Inc. 6FBA and HF were purified by recrystallization. $N, N$-dimethylacetamide (DMAc) and $N$-methyl-2-pyrrolidinone (NMP) were purchased from Aldrich Chemical Co., Inc. Triethylamine (TEA) and pyridine were purchased from Ishizu Co. Ltd. Pyridine was purified by distillation over potassium hydroxide. DMAc and TEA were purified by distillation over potassium hydroxide under nitrogen atmosphere with removing dissolved oxygen. NMP was used as received. Dichlorobis(triphenylphosphine)palladium(II), triphenylphosphine and copper(I) iodide were obtained from Aldrich Chemical Co., Inc.

\section{Synthesis of Phenylethynylphenol (PEP)}

The procedure of PEP was modified from the method of Lee. ${ }^{16}$ 1-Bromo-4-acetoxybenzene (BAB) was synthesized from 4-bromophenol according to the previous procedure. ${ }^{16,17}$

$8.0 \mathrm{~g}$ of BAB $(37 \mathrm{mmol}), 0.49 \mathrm{~g}$ of triphenylphosphine $(1.9 \mathrm{mmol})$ and $14 \mathrm{~mL}$ of DMAc were placed in a $200 \mathrm{~mL}$ three-neck flask equipped with a condenser, a thermometer, an additional funnel and a nitrogen inlet tube. This solution was treated by freezethaw cycles to remove traces of dissolved oxygen. $0.26 \mathrm{~g}$ of dichlorobis(triphenylphosphine)palladium(II) $(0.37 \mathrm{mmol})$ washed with $28 \mathrm{~mL}$ of TEA, $0.088 \mathrm{~g}$ of copper(I) iodide $(0.47 \mathrm{mmol})$ and $28 \mathrm{~mL}$ of TEA were added into this solution. This mixture was treated further by freeze-thaw cycles. $4.6 \mathrm{~g}$ of phenylacetylene $(45 \mathrm{mmol})$ and $4.7 \mathrm{~mL}$ of DMAc were placed into a $50 \mathrm{~mL}$ flask, and treated by freeze-thaw cycles. This phenylacetylene solution was added dropwise into the mixture at $70^{\circ} \mathrm{C}$ while stirring, and then maintained at $70^{\circ} \mathrm{C}$ for $24 \mathrm{~h}$. After being allowed to cool, the reaction mixture was filtered to remove inorganic salts and then TEA was stripped off under reduced pressure. The obtained viscous liquid was poured into acidic water, and the organic layer was extracted with dichloromethane. The solution was dried over sodium sulfate and the dichloromethane was evaporated. The obtained brown solid was recrystallized from 2-propanol. $5.2 \mathrm{~g}$ of 4-acetoxy-phenylethynylbenzene was obtained $(59 \%$ yield). The product characteristics were as follows; $T_{\mathrm{m}}$ : $104^{\circ} \mathrm{C}$, FT-IR $\left(\mathrm{KBr}, \mathrm{cm}^{-1}\right)$ : 1753, 1502, 1371, 1200 ,
1014, 916, 849, 758, 692, 523.

Into a flask equipped with a condenser were placed $5.0 \mathrm{~g}$ of 4-acetoxy-phenylethynylbenzene $(21 \mathrm{mmol})$, $47 \mathrm{~mL}$ of THF and $47 \mathrm{~mL}$ of methanol. $3.7 \mathrm{~g}$ of sodium hydroxide $(93 \mathrm{mmol}$ ) dissolved in $31 \mathrm{~mL}$ of water was added to this solution. After being refluxed for $12 \mathrm{~h}$ with stirring, the reaction mixture was allowed to cool and poured into acidic water. The organic layer was extracted with dichloromethane and dried over sodium sulfate. After evaporating dichloromethane, the obtained solid was purified by recrystallization from the mixture of n-hexane and toluene. Yellow crystal of PEP was obtained at $3.3 \mathrm{~g}(80 \%$ yield $)$. The product characteristics were as follows; $T_{\mathrm{m}}: 128^{\circ} \mathrm{C}$ (lit. $\left.{ }^{17} 125^{\circ}\right) \mathrm{C}$, FTIR $\left(\mathrm{KBr}, \mathrm{cm}^{-1}\right)$ : 3423, 1606, 1591, 1510, 1439, 1371, $1252,1101,833,750,688,521,{ }^{1} \mathrm{H}$ NMR $\left(\mathrm{CDCl}_{3}\right.$, ppm): $4.93\left(\mathrm{~s}, 1 \mathrm{H}, \mathrm{H}^{\mathrm{f}}\right), 6.80\left(\mathrm{~d}, 2 \mathrm{H}, \mathrm{H}^{\mathrm{e}}\right), 7.30-7.34(\mathrm{~m}$, $3 \mathrm{H}, \mathrm{H}^{\mathrm{a}}$, and $\left.\mathrm{H}^{\mathrm{b}}\right), 7.42\left(\mathrm{~d}, 2 \mathrm{H}, \mathrm{H}^{\mathrm{d}}\right), 7.49\left(\mathrm{~d}, 2 \mathrm{H}, \mathrm{H}^{\mathrm{c}}\right)$.



Synthesis of 4,4'-Bis[4-(4-phenylethynylphenoxy)-2,3, 5,6-tetrafluorobenzoyl]diphenyl ether

$0.16 \mathrm{~g}$ of PEP $(0.83 \mathrm{mmol}), 0.057 \mathrm{~g}$ of potassium carbonate $(0.41 \mathrm{mmol}), 1.2 \mathrm{~mL}$ of NMP and $0.80 \mathrm{~mL}$ of toluene were placed into a $10 \mathrm{~mL}$ of flask equipped with Dean-Stark trap, a condenser and a nitrogen inlet tube. The mixture was refluxed for $3 \mathrm{~h}$ with eliminating by-produced water by azeotropic distillation and then toluene was distilled over. The mixture was allowed to cool and $0.23 \mathrm{~g}$ of $4,4^{\prime}$-bis $(2,3,4,5,6$ pentafluorobezoyl)diphenyl ether (BPDE) $(0.41 \mathrm{mmol})$ synthesized according to the previous procedure ${ }^{5}$ was added into the mixture. The reaction was kept at $120^{\circ} \mathrm{C}$ for $15 \mathrm{~h}$. The reaction mixture was allowed to cool to room temperature and poured into methanol. The precipitates were collected by filtration, and washed with water containing $1 \%$ acetic acid and water. Pale brown solid of 4,4'-bis[4-(4-phenylethynylphenoxy)2,3,5,6-tetrafluorobenzoyl]diphenyl ether was obtained at $0.27 \mathrm{~g}(71 \%$ yield $)$. The product characteristic was as follows; Calcd for $\mathrm{C}_{54} \mathrm{~F}_{8} \mathrm{H}_{24} \mathrm{O}_{5}$ : C, 71.68\%; F, $16.81 \%$; H, 2.66\%; O, 8.85\%. Found: C, 70.94\%; F, $17.11 \%, \mathrm{H}, 2.94 \%$, O, 9.01\%. FT-IR $\left(\mathrm{KBr}, \mathrm{cm}^{-1}\right)$ : 1678, 1587, 1496, 1319, 1238, 1167, 1107, 989, 831, 692, ${ }^{1} \mathrm{H}$ NMR $\left(\mathrm{CDCl}_{3}, \mathrm{ppm}\right): 7.00\left(\mathrm{~d}, 4 \mathrm{H}, \mathrm{H}^{\mathrm{e}}\right), 7.19$ (d, $\left.4 \mathrm{H}, \mathrm{H}^{\mathrm{g}}\right), 7.33-7.35\left(\mathrm{~m}, 2 \mathrm{H}, \mathrm{H}^{\mathrm{a}}\right.$, and $\left.4 \mathrm{H}, \mathrm{H}^{\mathrm{b}}\right), 7.51(\mathrm{~d}$, $\left.4 \mathrm{H}, \mathrm{H}^{\mathrm{d}}\right), 7.53\left(\mathrm{~d}, 4 \mathrm{H}, \mathrm{H}^{\mathrm{c}}\right), 7.93\left(\mathrm{~d}, 4 \mathrm{H}, \mathrm{H}^{\mathrm{f}}\right),{ }^{19} \mathrm{~F}$ NMR $\left(\mathrm{CDCl}_{3}, \mathrm{ppm}\right):-142\left(\mathrm{~d}, 4 \mathrm{~F}, \mathrm{~F}^{\mathrm{a}}\right),-130\left(\mathrm{~d}, 4 \mathrm{~F}, \mathrm{~F}^{\mathrm{b}}\right)$. 




\section{Synthesis of Polymers}

Synthesis of PEK(6FBA)-PEPn $=20$ is given as a typical example as follows.

$0.090 \mathrm{~g}$ of PEP $(0.46 \mathrm{mmol})$ was added into the solution of $0.026 \mathrm{~g}$ of potassium hydroxide $(0.46 \mathrm{mmol})$ and $20 \mathrm{~mL}$ of methanol. The mixture was stirred for $1 \mathrm{~h}$ at room temperature. Methanol and by-produced water were evaporated and phenylethynylphenoxide was prepared.

Into a $25 \mathrm{~mL}$ flask equipped with Dean-Stark trap, a condenser and a nitrogen inlet tube were placed $0.43 \mathrm{~g}$ of $6 \mathrm{FBA}(1.28 \mathrm{mmol}), 0.18 \mathrm{~g}$ of potassium carbonate $(1.28 \mathrm{mmol}), 4.7 \mathrm{~mL}$ of NMP and $2.4 \mathrm{~mL}$ of toluene. The mixture was refluxed for $3 \mathrm{~h}$ with eliminating by-produced water by azeotropic distillation and then toluene was distilled over. After being allowed to cool at $80^{\circ} \mathrm{C}, 0.75 \mathrm{~g}$ of BPDE $(1.34 \mathrm{mmol})$ was added into the mixture. The polymerization was kept at $80^{\circ} \mathrm{C}$ for $20 \mathrm{~h}$. Then $0.060 \mathrm{~g}$ of phenylethynylphenoxide $(0.26 \mathrm{mmol})$ was added into the mixture. The reaction was kept at $120^{\circ} \mathrm{C}$ for $15 \mathrm{~h}$. The reaction mixture was allowed to cool to room temperature and poured into methanol. The precipitated polymer was collected by filtration, and then washed with water containing $1 \%$ acetic acid and water. $0.84 \mathrm{~g}$ of PEK(6FBA)-PEPn $=20$ was obtained ( $73 \%$ yield). The product characteristics were as follows; FT-IR $\left(\mathrm{KBr}, \mathrm{cm}^{-1}\right)$ : 1680, 1587, 1495, $1414,1319,1240,1174,1107,991,874,831,650,{ }^{1} \mathrm{H}$ NMR and ${ }^{13} \mathrm{C}$ NMR were shown in Figures 4 and $5 .{ }^{19} \mathrm{~F}$ NMR ( $\left.\mathrm{CDCl}_{3}, \mathrm{ppm}\right):-151$ (d, Ar-F), -140 (d, Ar-F), $-63.8\left(\mathrm{~s}, \mathrm{CF}_{3}\right)$.

\section{Characterization}

NMR spectra were recorded on a Varian Unity500 operating at $500 \mathrm{MHz}\left({ }^{1} \mathrm{H}\right), 75 \mathrm{MHz}\left({ }^{13} \mathrm{C}\right)$ and $470 \mathrm{MHz}\left({ }^{19} \mathrm{~F}\right) . \mathrm{CDCl}_{3}$ was used as the measuring solvent. FT-IR measurements were performed on JASCO FT-IR 350. Glass transition temperature $\left(T_{\mathrm{g}}\right)$ and decomposition temperature were measured on PerkinElmer DSC 7 and TGA 7 at a scanning rate of $20^{\circ} \mathrm{C}$ $\mathrm{min}^{-1}$ in nitrogen atmosphere. Softening temperature $\left(T_{\mathrm{s}}\right)$ was measured on a Yanaco MP-500D. $T_{\mathrm{s}}$ was defined as the temperature at which the polymer began to soften. Thermal analyses were performed with powder samples. Molecular weights were measured on TOSO 8020 GPC. NMP was used as an eluent and column temperature was $40^{\circ} \mathrm{C}$. Molecular weight was calcu- lated with polystyrene standard. Dynamic mechanical measurement was performed on Orientech Rheovibron DDV-II -EP at $110 \mathrm{~Hz}$ with a scanning rate of $2^{\circ} \mathrm{C}$ $\min ^{-1}$. The mode of measurement was stress. The measured samples were films of which the average thickness was $37 \mu \mathrm{m}$. Solvent resistance was estimated by weighing insoluble part of the film after soaking for 1 $\mathrm{d}$ at room temperature in toluene. Crystallinity of the film was measured by WAXS diffractometer of Rigaku Gaiger flex $\left(\mathrm{Cu}-K_{\alpha} \lambda=1.5418 \AA\right)$. UV spectra of the films were measured on JASCO V-570. The film thickness was $2 \mu \mathrm{m}$.

\section{RESULTS AND DISCUSSION}

\section{Cross-Linking Behavior of Model Compound}

4,4'-Bis[4-(4-phenylethynylphenoxy)-2,3,5,6-tetrafluorobenzoyl]diphenyl ether was synthesized from BPDE and PEP as a model compound to know the thermally cross-linking behavior of phenylethynyl moiety. The synthetic procedures of this model compound are shown in Scheme 2. The thermally cross-linking reaction of this model compound was followed by isothermal curing on DSC at 330, 340, and $360^{\circ} \mathrm{C}$. The exothermic peak was observed due to cross-linking reaction as shown in Figure 1. Conversion of cross-linking was calculated on the basis of the heat content of the exothermic peak. The crosslinking reaction of the model compound obeys the first-order reaction kinetics as shown in Figure 2. The first-order rate constants at 330,340 , and $360^{\circ} \mathrm{C}$ are estimated as $0.79 \times 10^{-3} \mathrm{sec}^{-1}, 1.35 \times 10^{-3} \mathrm{sec}^{-1}$, and $3.41 \times 10^{-3} \mathrm{sec}^{-1}$, respectively. From the temperature dependence of rate constant, the activation energy $(\triangle E$ a) for thermally cross-linking of phenylethynyl moiety can be calculated as $156 \mathrm{~kJ} \mathrm{~mol}^{-1}$. $\Delta E$ a of this model compound is in good agreement with that of phenylethynyl terminated imide oligomers which is $153 \mathrm{~kJ} \mathrm{~mol}^{-1}$ as reported. ${ }^{18}$

The structural change of model compound during curing was followed by FT-IR. The spectra of uncured and cured model compound have no difference in except for wavenumber around $1650 \mathrm{~cm}^{-1}$ and the spectrum of the model compound cured at $320^{\circ} \mathrm{C}$ for $2 \mathrm{~h}$ is shown in Figure 3. Previous study has reported that phenylethynyl moiety turns thermally into chain extension, branching and cross-linking through the formation of $\mathrm{C}=\mathrm{C}$ double bond and that the structure of cross- 




Scheme 2. Synthesis of model compound.



Figure 1. DSC trace of model compound at $330^{\circ} \mathrm{C}$.

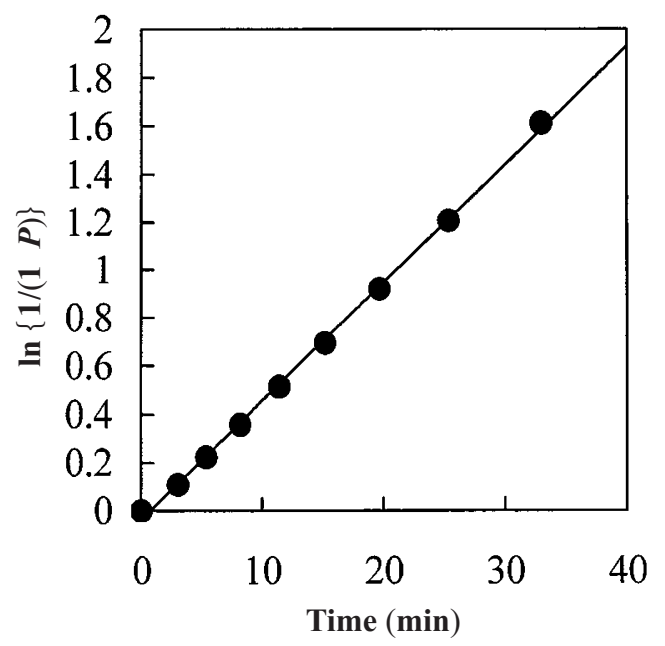

Figure 2. Conversion of cross-linking reaction of model compound at $330^{\circ} \mathrm{C}$ applied to primary reaction formula.

links were polyene, aromatic ring and so on. ${ }^{11}$ The carbonyl stretching vibration is observed at $1680 \mathrm{~cm}^{-1}$ in both spectrum of the uncured and cured compound. This peak has a shoulder at $c a .1650 \mathrm{~cm}^{-1}$ and so it is resolved into several peaks by Lorentz function. In the spectrum of the uncured compound a peak except for $1680 \mathrm{~cm}^{-1}$ appears at $c a .1650 \mathrm{~cm}^{-1}$ to be assigned to overtone or combination peak of aromatic ring. After curing, a new peak appears at $1640 \mathrm{~cm}^{-1}$. This peak is able to be assigned to $\mathrm{C}=\mathrm{C}$ double bond stretching vibration. The appearance of this peak strongly suggested that $\mathrm{C} \equiv \mathrm{C}$ triple bond in phenylethynyl group undergoes the cross-linking reaction through the conversion into $\mathrm{C}=\mathrm{C}$ double bond.
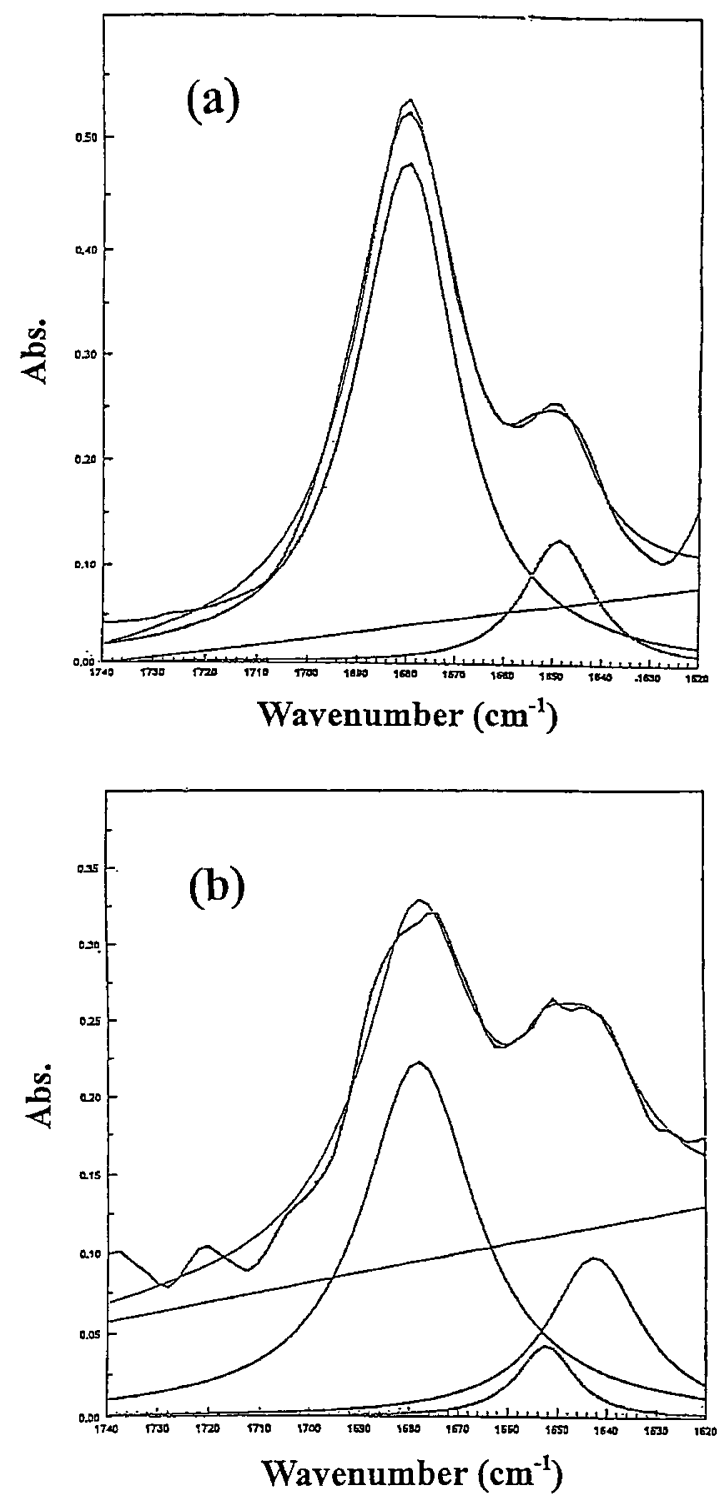

Figure 3. IR spectra of model compound (a) uncured and (b) cured at $320^{\circ} \mathrm{C}$ for $2 \mathrm{~h}$.

\section{Polymer Synthesis}

PEK-PEPs were synthesized as shown in Scheme 3. 6FBA and HF were used as bisphenols. The degree of polymerization was adjusted by the feed ratio between BPDE and bisphenol. Polymer codes were named according to the bisphenol and the number-average degree of polymerization $\left(\mathrm{DP}_{\mathrm{n}}\right)$ calculated from the feed ratio. For instance PEK(6FBA)-PEPn $=20$ in which 


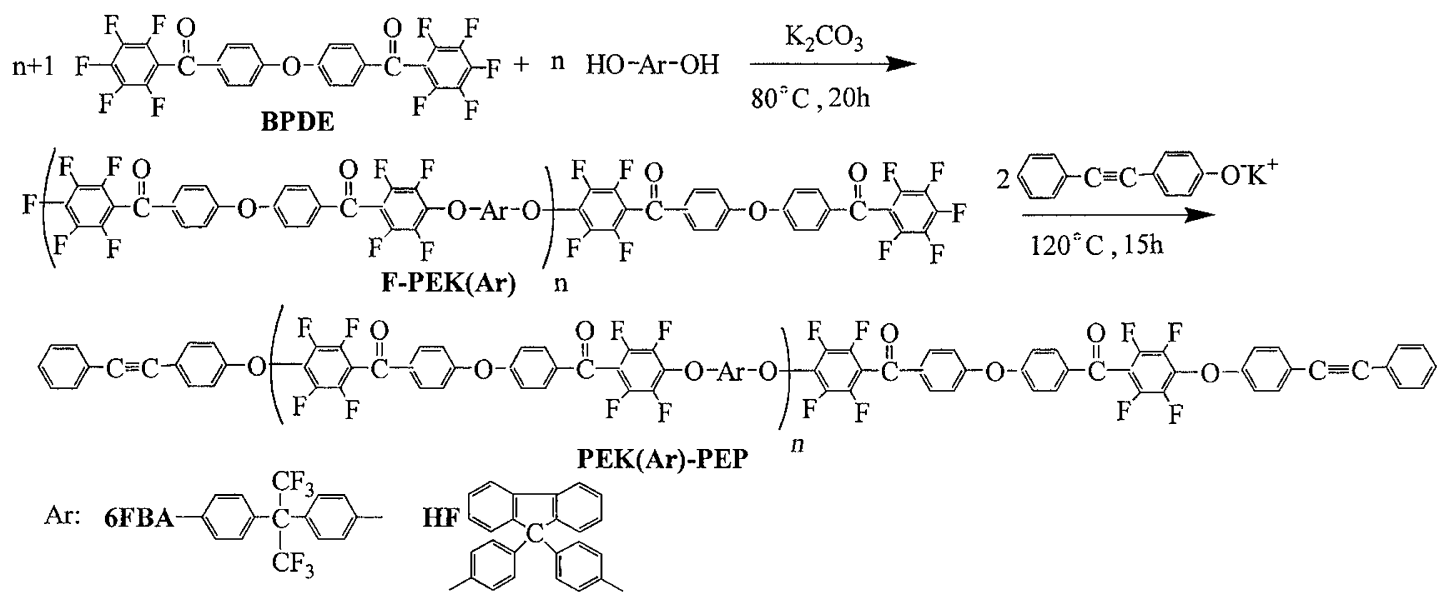

Scheme 3. Synthesis of cross-linkable fluorine-containing PEKs.
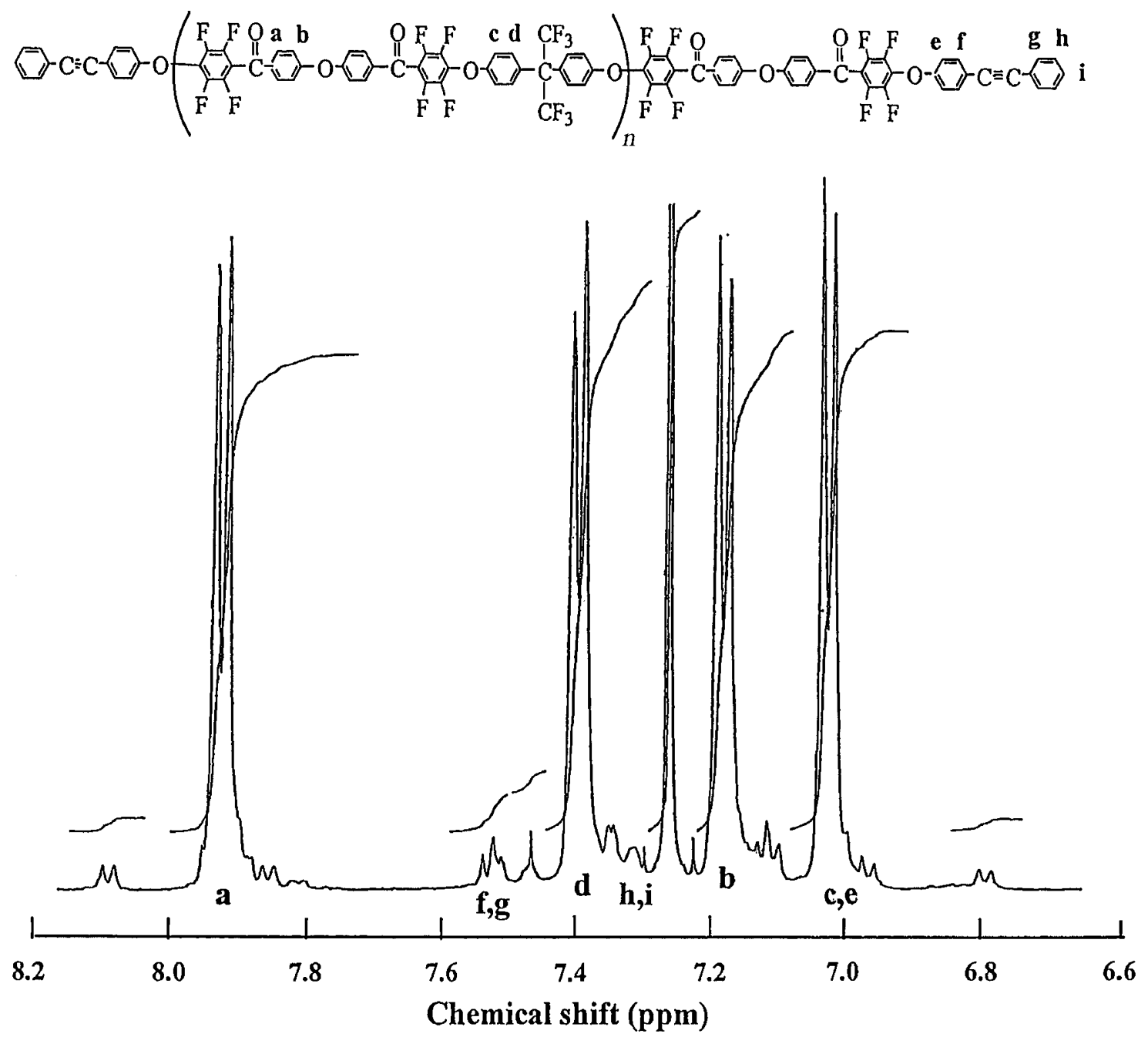

Figure 4. ${ }^{1} \mathrm{H}$ NMR spectrum of $\mathrm{PEK}(6 \mathrm{FBA})-\mathrm{PEPn}=20$.

6FBA describes the used bisphenol and $\mathrm{n}=20$ stands for the calculated $\mathrm{DP}_{\mathrm{n}}$. The chemical structure of PEKPEPs is confirmed by FT-IR, ${ }^{1} \mathrm{H}$ and ${ }^{13} \mathrm{C}$ NMR. ${ }^{1} \mathrm{H}$ and ${ }^{13} \mathrm{C}$ NMR spectra of PEK(6FBA)-PEPn $=20$ are shown in Figures 4 and 5. In Figure 4, there exists two unassignable signals at 6.8 and $8.1 \mathrm{ppm}$ of which the in- tensities are very weak. They might be signals of contaminants. In this case, $\mathrm{DP}_{\mathrm{n}}$ calculated from the NMR result is 24 .

Table I summarized the results of PEK-PEPs synthesis. Molecular weight can be controlled by the feed ratio between BPDE and bisphenol. $T_{\mathrm{g}}$ of uncured PEK- 

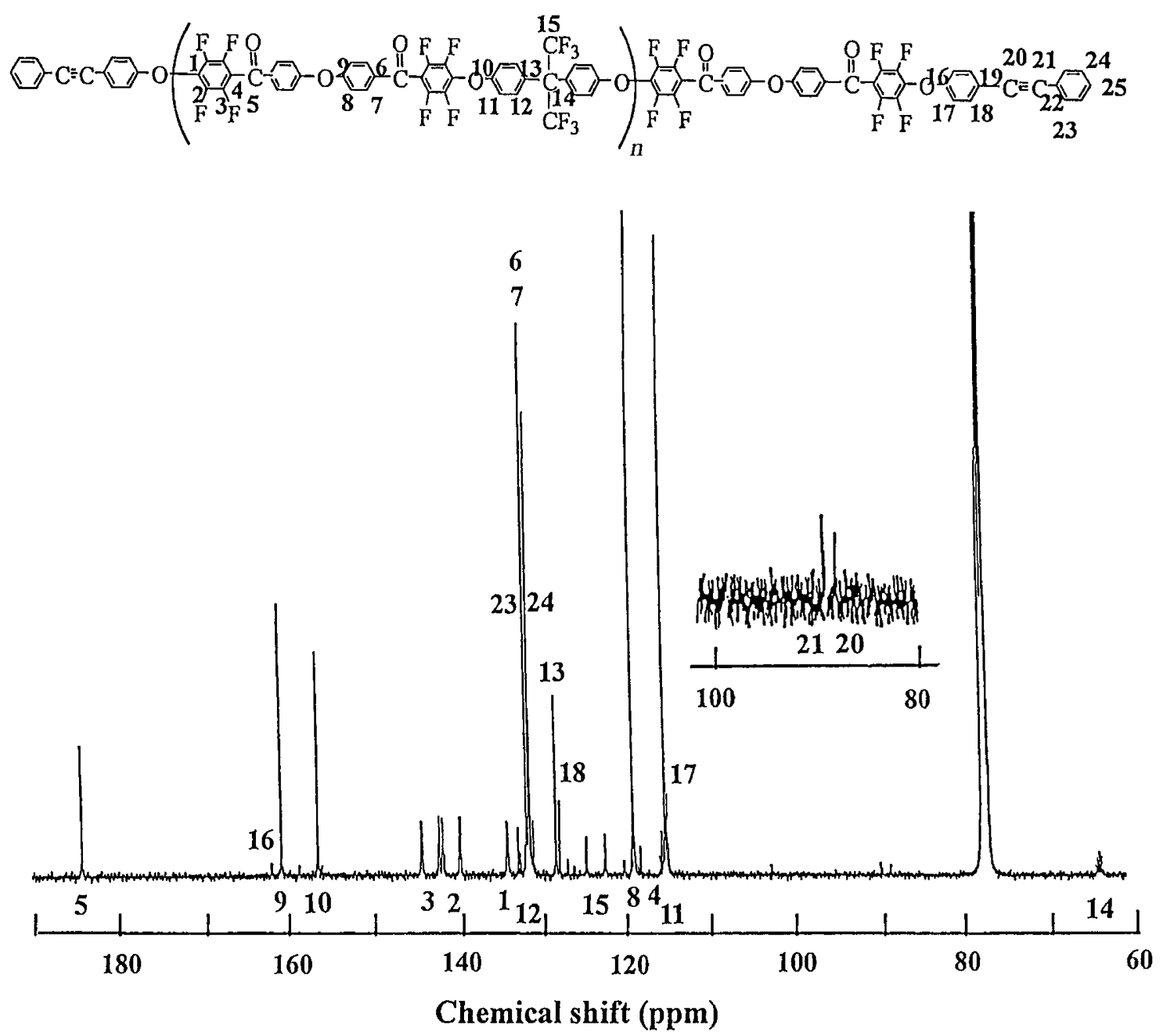

Figure 5. ${ }^{13} \mathrm{C}$ NMR spectrum of PEK(6FBA)-PEPn $=20$.

Table I. Synthesis of PEK-PEP

\begin{tabular}{ccccccc}
\hline Polymer code & $\frac{M_{\mathrm{n}}^{\mathrm{b}}}{\times 10^{-3}}$ & $\frac{M_{\mathrm{w}}}{\times 10^{-3}}$ & $M_{\mathrm{w}} / M_{\mathrm{n}}$ & $\frac{T_{\mathrm{g}}{ }^{\mathrm{c}}}{{ }^{\circ} \mathrm{C}}$ & $\frac{T_{\mathrm{s}}{ }^{\mathrm{d}}}{{ }^{\circ} \mathrm{C}}$ & $\frac{\text { Yield }}{\%}$ \\
\hline $\begin{array}{c}\text { PEK(6FBA)-PEP } \\
n=10\end{array}$ & 5.69 & 8.30 & 1.46 & 145 & 152 & 40.1 \\
$\begin{array}{c}\text { PEK(6FBA)-PEP } \\
n=20\end{array}$ & 13.6 & 22.7 & 1.67 & 179 & 182 & 72.5 \\
$\begin{array}{c}\text { PEK(6FBA)-PEP } \\
n=40\end{array}$ & 26.6 & 44.1 & 1.66 & 181 & 197 & 67.3 \\
$\begin{array}{c}\text { PEK(HF)-PEP } \\
n=20\end{array}$ & 10.7 & 21.0 & 1.96 & 210 & 216 & 66.5 \\
\hline
\end{tabular}

${ }^{\text {a }}$ Polymer code was showed in Scheme $3 .{ }^{b}$ Determined by GPC calibrated with polystyrene standard eluted with NMP at $40^{\circ} \mathrm{C}$. ${ }^{\mathrm{c}}$ Glass transition temperature was measured by DSC at a heating rate of $20^{\circ} \mathrm{C} \mathrm{min}^{-1}$. ${ }^{\mathrm{d}}$ Softening temperature was measured by optical microscope equipped with hotting stage.

PEP is dependent on not only the molecular weight but also the structure of bisphenol. $T_{\mathrm{g}}$ of PEK(6FBA)-PEP increases with the molecular weight from 145 to $181^{\circ} \mathrm{C}$. $T_{\mathrm{s}}$ has the same tendency as $T_{\mathrm{g}}$. Concerning to the structure of bisphenol, HF leads to higher $T_{\mathrm{g}}$ due to the bulky cardo structure.

\section{Cross-Linking Behavior of PEK-PEP}

The cross-linking behavior of PEK-PEP was also followed by isothermal curing on DSC measurement at $320^{\circ} \mathrm{C}$. The exothermic peak was observed which is attributed to the cross-linking reaction as well as the model compound. The cross-linking reaction of PEKPEP does not obey the first-order reaction kinetics differed from the model compound as described above. In 
Table II. Thermal properties of PEK-PEP

\begin{tabular}{|c|c|c|c|c|c|}
\hline \multirow{2}{*}{ Polymer code ${ }^{\mathrm{a}}$} & \multicolumn{2}{|c|}{$T_{\mathrm{g}} \mathrm{b} /{ }^{\circ} \mathrm{C}$} & \multicolumn{2}{|c|}{$T_{\mathrm{s}} \mathrm{c} /{ }^{\circ} \mathrm{C}$} & \multirow{2}{*}{$\begin{array}{c}T_{\mathrm{d}} 10^{\mathrm{d}} /{ }^{\circ} \mathrm{C} \\
\text { Cured }^{\mathrm{e}}\end{array}$} \\
\hline & Uncured & Cured $^{\mathrm{e}}$ & Uncured & Cured $^{\mathrm{e}}$ & \\
\hline $\begin{array}{c}\mathrm{PEK}(6 \mathrm{FBA})-\mathrm{PEP} \\
n=10\end{array}$ & 145 & 170 & 152 & $\mathrm{ND}^{\mathrm{f}}$ & 544 \\
\hline $\begin{array}{c}\mathrm{PEK}(6 \mathrm{FBA})-\mathrm{PEP} \\
n=20\end{array}$ & 179 & 186 & 182 & ND & 559 \\
\hline $\begin{array}{c}\text { PEK(6FBA)-PEP } \\
n=40\end{array}$ & 181 & 192 & 197 & ND & 558 \\
\hline $\begin{array}{c}\text { PEK(HF)-PEP } \\
n=20\end{array}$ & 210 & 223 & 216 & ND & 598 \\
\hline
\end{tabular}

${ }^{\text {a }}$ Polymer code was showed in Scheme 3. ${ }^{\mathrm{b}}$ Glass transition temperature was measured by DSC at a heating rate of $20^{\circ} \mathrm{C} \mathrm{m^{-1 }}$. ${ }^{\mathrm{c}}$ Softening temperature was measured by optical microscope equipped with hotting stage. ${ }^{\mathrm{d}}$ Temperature of $10 \% \mathrm{wt}$ loss was measured by TGA at a heating rate of $20^{\circ} \mathrm{C} \mathrm{min}^{-1}$ in nitrogen. ${ }^{\mathrm{e}} \mathrm{Cured}$ at $320^{\circ} \mathrm{C}$ for $2 \mathrm{~h}$. ${ }^{\mathrm{f}}$ Not detected under the decomposition temperature.

the case of the cross-linking reaction of polymer end groups, the mobility of polymer chain decreases with increasing conversion of the cross-linking reaction, and thereby this results in the decrease of the reaction rate.

Thermal properties of PEK-PEPs are shown in Table II. Curing at $320^{\circ} \mathrm{C}$ leads to a drastic increase of $T_{\mathrm{g}}$. Ts of cured PEK-PEPs is not observed under their thermal decomposition. $T_{\mathrm{g}}$ of uncured PEK-PEPs is dependent on not only molecular weight but also the structure of bisphenol as described above. $T_{\mathrm{g}}$ of cured PEK-PEPs is also dependent on the structure of bisphenol. Figure 6 plots the increase of $T_{\mathrm{g}}$ against the density of cross-linking for PEK(6FBA)-PEPn $=20$ and $\mathrm{PEK}(\mathrm{HF})-\mathrm{PEPn}=20$ during curing at $320^{\circ} \mathrm{C}$. The density of the cross-linking is estimated from conversion of the cross-linking reaction. $T_{\mathrm{g}}$ increases lineally with the density of the cross-linking in both polymers. The relation between $T_{\mathrm{g}}$ and cross-linking density for rubber had been proposed, so-called configurational entropy theory as described below. ${ }^{19}$

$$
\begin{array}{r}
\left\{T_{\mathrm{g}}(X)-T_{\mathrm{g}}(0)\right\} / T_{\mathrm{g}}(0)=(K M X / \gamma) /(1-K M X / \gamma) \\
=\alpha X /(1-\alpha X) \\
\because \quad T_{\mathrm{g}}(0) / T_{\mathrm{g}}(X)=-\alpha X+1
\end{array}
$$

where $\alpha=\mathrm{KM} / \gamma$

Here, $T_{\mathrm{g}}(\mathrm{X})$ is the glass transition temperature with degree of cross-linking.

$T_{\mathrm{g}}(0)$ is the glass transition temperature uncrosslinked.

$X$ is number of cross-links per gram.

$M$ is molecular weight of a residue.

$\gamma$ is number of flexible bonds per residue.

$K$ is constant.

The change of $T_{\mathrm{g}}$ of PEK-PEPs is analyzed according to this theory assuming that one cross-link is made from three PEP end groups, which is borne out by the results of FT-IR as mentioned above, and $\gamma=13$. The

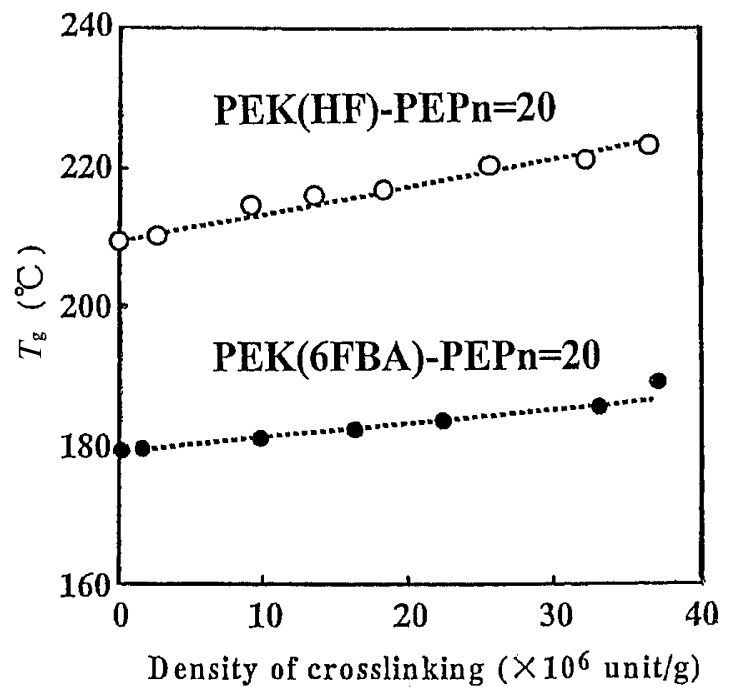

Figure 6. Relationship between $T_{\mathrm{g}}$ and cross-linking density (Dash-lines show the calculated lines Circles show the measured values).

following equations are obtained.

$$
\begin{gathered}
\text { PEK(6FBA)-PEPn }=20 \\
T_{\mathrm{g}}(0) / T_{\mathrm{g}}(X)=-426 X+1 \\
\text { PEK(HF)-PEPn }=20 \\
T_{\mathrm{g}}(0) / T_{\mathrm{g}}(X)=-793 X+1
\end{gathered}
$$

The obtained lines are also showed in Figure 6. The increase of $T_{\mathrm{g}}$ during curing seemed to be accounted for by the configurational entropy theory. However, $K$ constant of PEK-PEP is quite different from that of rubber reported. The cross-linking reaction leads to the increase of molecular weight of PEK-PEPs and this brings about the increase of $T_{\mathrm{g}}$. The contribution to the increase of $T_{\mathrm{g}}$ caused by molecular weight is not involved in this theory, and hence this may be a main reason for the large difference on the $K$ constant. 
Table III. Solvent resistance of PEK(6FBA)-PEPn=20

\begin{tabular}{|c|c|c|}
\hline Curing time $^{\mathrm{a}}$ & Conv. $^{\text {b }}$ & Insoluble part into toluene \\
\hline $\min$ & $\%$ & wt $\%$ \\
\hline 0 & 0 & 0 \\
\hline 30 & 21 & 69 \\
\hline 60 & 52 & 80 \\
\hline 120 & 91 & 100 \\
\hline 200 & 100 & 100 \\
\hline
\end{tabular}
mated from heat content of exothermic peak measured on DSC. ${ }^{\mathrm{c}}$ Estimated by weighing the film after soaking for $1 \mathrm{~d}$ at room temperature.

Table IV. Solubility of PEK-PEP

\begin{tabular}{lcc}
\hline Solvent & Uncured & Cured $^{\mathrm{a}}$ \\
\hline NMP & $\mathrm{S}^{\mathrm{b}}$ & $\mathrm{I}^{\mathrm{b}}$ \\
DMAc & $\mathrm{S}$ & $\mathrm{I}$ \\
Chloroform & $\mathrm{S}$ & $\mathrm{I}$ \\
THF & $\mathrm{S}$ & $\mathrm{I}$ \\
Toluene & $\mathrm{S}$ & $\mathrm{I}$ \\
\hline${ }^{\mathrm{a}}$ Cured at $320^{\circ} \mathrm{C}$ for $2 \mathrm{~h}^{\mathrm{b}} \mathrm{S}$ : soluble, I: insoluble at $25^{\circ} \mathrm{C}$
\end{tabular}

${ }^{\mathrm{a}} \mathrm{Cured}$ at $320^{\circ} \mathrm{C}$ for $2 \mathrm{~h}$. ${ }^{\mathrm{b}} \mathrm{S}$ : soluble, I: insoluble at $25^{\circ} \mathrm{C}$.

\section{Characterization}

Solvent resistance of PEK-PEP was firstly evaluated by the qualitative solubility test in excess of toluene. The thin film of PEK(6FBA)-PEPn $=20$ was prepared by casting of toluene solution and cured at $320^{\circ} \mathrm{C}$. Insoluble part in toluene increases with curing time as summarized in Table III, that is to say, solubility decreases with the conversion of cross-linking reaction. After curing for $120 \mathrm{~min}$, the film gets completely insoluble in toluene. Table IV shows the results of the solubility test in several solvents for the uncured and cured PEK(6FBA)-PEPn $=20$ at $320^{\circ} \mathrm{C}$ for $120 \mathrm{~min}$. The uncured PEK(6FBA)-PEPn $=20$ possesses the outstanding solubility into many solvents. On the other hand, the cured PEK(6FBA)-PEPn $=20$ is completely insoluble in even polar aprotic solvent such as DMAc and NMP. Thermal cross-linking reaction affords PEK-PEP with the excellent solvent resistance.

Thermal stability estimated by TGA is also shown in Table II. Temperatures of $10 \%$ weight loss in nitrogen (Td10) of cured PEK-PEP are quite high, which is in the range from 544 to $598^{\circ} \mathrm{C}$. We have reported that Td10 of the F-PEKs which do not possess the phenylethynyl moiety ranges from 499 to $553^{\circ} \mathrm{C} .^{5}$ Compared with these Td10s, thermal stability of PEKPEP is improved by about $40^{\circ} \mathrm{C}$ due to the crosslinking. The TGA curve of the cured PEK-PEP is shown in Figure 7 with that of F-PEK. It is particularly noteworthy that the cured PEK-PEP exhibits very high char yield at high temperature.

Dynamic mechanical scans of the uncured and cured

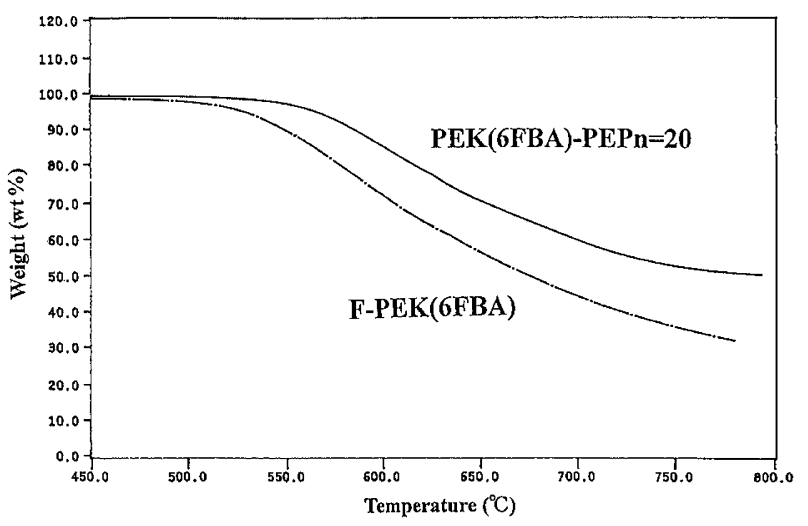

Figure 7. TGA thermo-grams of cured PEK(6FBA)-PEPn $=20$ and F-PEK(6FBA).
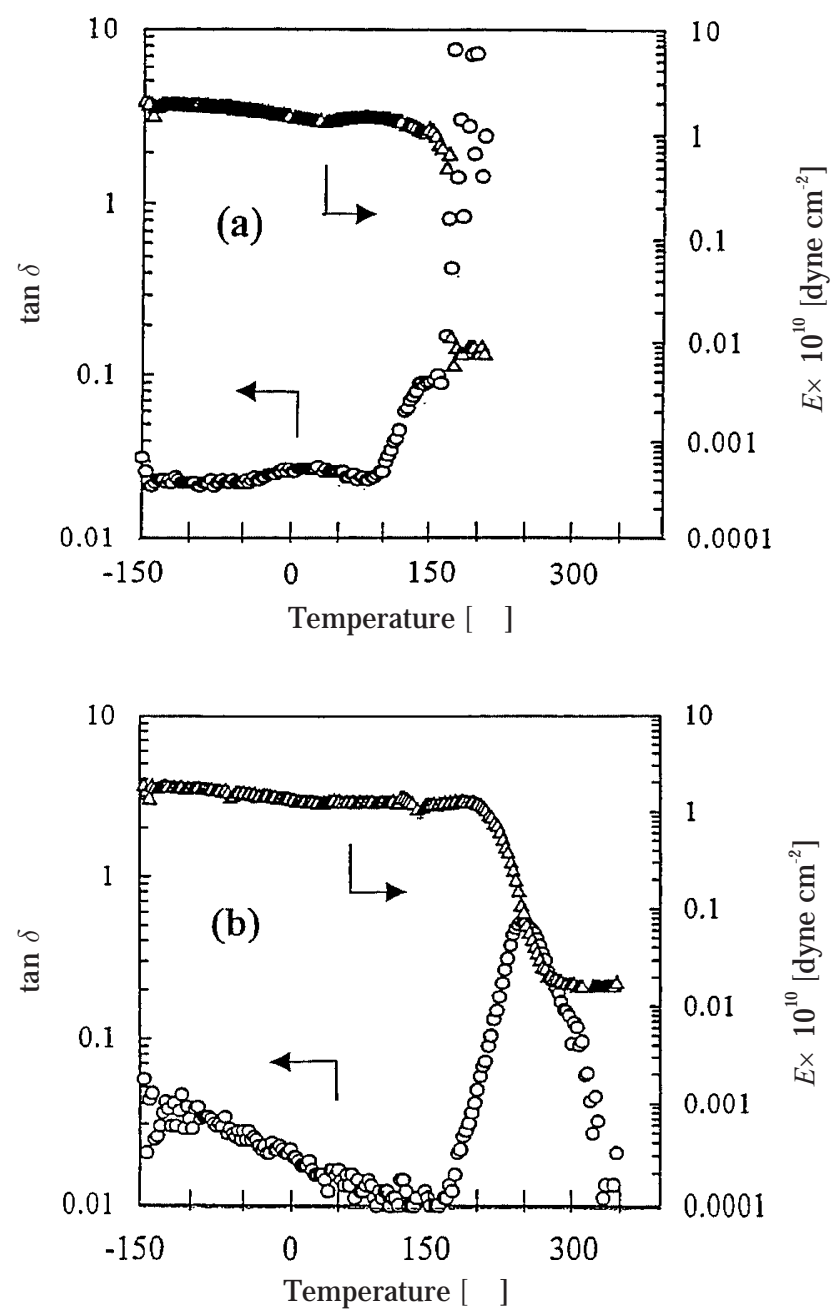

Figure 8. Dynamic mechanical scan for PEK(6FBA)-PEPn = 20 (a) uncured and (b) cured at $320^{\circ} \mathrm{C}$ for $2 \mathrm{~h}$ at $110 \mathrm{~Hz}$ and heating rate of $2^{\circ} \mathrm{C} \mathrm{min}{ }^{-1}$. Film thickness was $37 \mu \mathrm{m}$.

PEK(6FBA)-PEPn $=20$ film are shown in Figure 8. Dynamic modulus at $25^{\circ} \mathrm{C}$ of the uncured and cured PEK-PEP are $1.42 \times 10^{10}$ dyne $\mathrm{cm}^{-2}$ and $1.30 \times 10^{10}$ dyne $\mathrm{cm}^{-2}$, respectively. Though the modulus of the uncured PEK-PEP decreases gradually over $160^{\circ} \mathrm{C}$, that of cured PEK-PEP is kept up to $200^{\circ} \mathrm{C}$ due to the shift of $\alpha$ relaxation toward higher temperature correspond- 


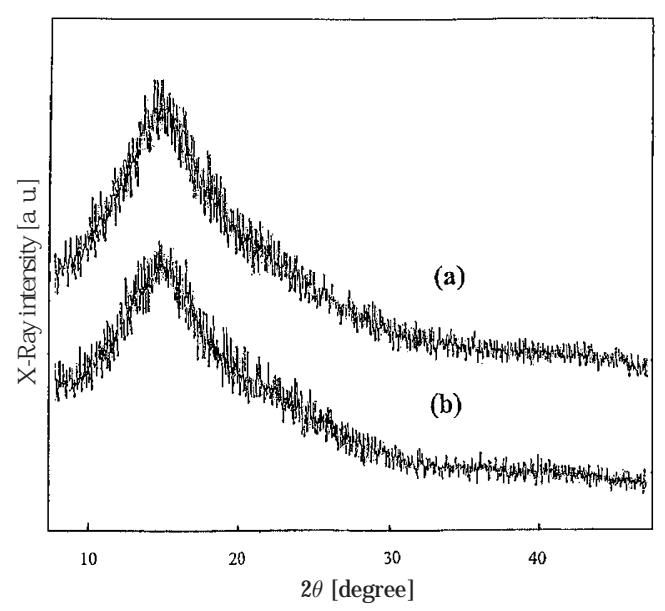

Figure 9. WAX intensity profiles of PEK(6FBA)-PEPn $=20$ (a) uncured and (b) cured at $320^{\circ} \mathrm{C}$ for $2 \mathrm{~h}$.



Figure 10. Absorption spectrum of $\operatorname{PEK}(6 \mathrm{FBA})-\operatorname{PEPn}=20$ (a) uncured and (b) cured at $320^{\circ} \mathrm{C}$ for $2 \mathrm{~h}$. Film thickness was $2 \mu \mathrm{m}$.

ing to glass transition. $\beta$ relaxation is observed at $c a$. $30^{\circ} \mathrm{C}$ in the uncured PEK-PEP. This lower relaxation is attributed to the conformation change of the diphenyl ether moiety. ${ }^{20}$ In the scan of the cured PEK-PEP, the $\beta$ relaxation disappears, though diphenyl ether moiety does not take part in the cross-linking reaction. The complete disappearance of $\beta$ relaxation also shows that the mobility of polymer chain is restricted by crosslinking.

Crystallinity was measured by WAXS diffractometer. The WAXS patterns of the uncured and cured PEK(6FBA)-PEPn $=20$ film are shown in Figure 9. Any diffraction arose from the crystallite is not observed at all and only the broad hallo arose from amorphous region is observed in both the films. Both the uncured and cured PEK-PEP films are not crystalline and show excellent transparency.

Though uncured PEK-PEP film was almost colorless, cured one was slightly yellow. Absorption spectra of uncured and cured film of PEK(6FBA)-PEPn = 20 are shown in Figure 10. These films exhibit $\pi-\pi^{*}$ absorption at $298 \mathrm{~nm}$. The serious difference is not observed between uncured and cured films and the red sift of $\pi-\pi^{*}$ absorption is not occurred. The formation of the aromatic ring or polyene structure is confirmed by IR as described, whereas these cross-linked structures do not affect the absorption spectrum due to the low concentration.

\section{CONCLUSION}

Cross-linkable fluorine-containing PEKs are synthesized by introducing phenylethynyl end group. Crosslinking reaction occurs over $320^{\circ} \mathrm{C}$ and it brings about not only the outstanding solvent resistance but also the increase of $T_{\mathrm{g}}$. Relationship between the cross-linking density and $T_{\mathrm{g}}$ can be fundamentally interpreted by configurational entropy theory. Furthermore, the cured PEK-PEPs possess excellent thermal stability with the $10 \%$ weight loss temperature in the range from 544 to $598^{\circ} \mathrm{C}$.

Acknowledgment. The authors are very grateful to Nippon Shokubai Co. Ltd. for the gift of 2,3,4,5,6pentafluorobenzoic acid and also to Mr. Yasunori Okumura of Nippon Shokubai Co. Ltd. for the measurement of GPC.

\section{REFERENCES}

1. M. Bruma, J. W. Fitch, and P. E. Cassidy, J. Macromol. Sci., Rev. Macromol. Chem. Phys., C36, 119 (1996).

2. P. E. Cassidy, J. Macromol. Sci., Rev. Macromol. Chem. Phys., C34, 1 (1994).

3. P. E. Cassidy, T. M. Aminabhavi, and J. M. Farley, J. Macromol. Sci., Rev. Macromol. Chem. Phys., C29, 365 (1989).

4. F. W. Mercer, M. M. Fone, V. N. Reddy, and A. A. Goodwin, Polymer, 38, 1989 (1997)

5. K. Kimura, Y. Tabuchi, Y. Yamashita, P. E. Cassidy, J. W. Fitch III, and Y. Okumura, Polym. Adv. Tech., 11, 757 (2000).

6. For examples

a) R. B. Seymour and G. S. Krishenbaum, "High Performance Polymers: Their Origin and Development", Pooceedings of an American Chemical Society Symposium, Elsevier Science Publishing Co., New York, N.Y., 1986.

b) A. Ravve, "Principles of Polymer Chemistry," 2nd ed., Kluwer Academic Plenum Publishers, New York, N.Y., 2000.

7. J. W. Connell, J. G. Smith Jr., and P. M. Hergenrother, High Perform. Polym., 10, 273 (1998).

8. P. M. Hergenrother, R. G. Bryant, B. J. Jensen, and S. J. Havens, J. Polym. Sci., Part A: Polym. Chem., 32, 3061 (1994).

9. G. W. Meyer, T. E. Glass, H. J. Grubbs, and J. E. McGrath, J. Polym. Sci., Part A: Polym. Chem., 33, 2141 (1995).

10. P. M. Hergenrother and J. G. Smith Jr., Polymer, 22, 4857 (1994).

11. X. Fang, X. Q. Xie, C. D. Simone, M. P. Stevens, and D. A. Scola, Macromolecules, 33, 1671 (2000).

12. A. Ayambem, S. J. Mecham, Y. Sun, T. E. Glass, and J. E. McGrath, Polymer, 41, 5109 (2000). 
13. G. W. Meyer, B. Tan, and J. E. McGrath, High Perform. Polym., 6, 423 (1994).

14. G. W. Meyer, S. J. Pak, Y. J. Lee, and J. E. McGrath, Polymer, 36, 2303 (1995).

15. P. M. Hergenrother, J. W. Connell, and J. G. Smith Jr., Polymer, 41, 5073 (2000).

16. H. Lee, E. Lee, M. Lee, M. Oh, J. Ahn, S. G. Han, and H. G.
Kim, J. Polym. Sci., Part A: Polym. Chem., 36, 2881 (1998).

17. M. Jandke, P. Strohriegl, S. Berleb, E. Werner, and W. Brutting, Macromolecules, 31, 6434 (1998).

18. T. Takekoshi and J. M. Terry, Polymer, 35, 4874 (1994).

19. E. A. DiMarzio, J. Res. NBS A. Phys. Ch., 68, 611 (1964).

20. L. David and S. Etienne, Macromolecules, 25, 4302 (1992). 